\title{
Analysis of Knowledge of Menstruation, Hygiene Practices, and Perceptions in Adolescent Girls in India
}

\author{
Nicole Solvig ${ }^{1}$, Leeberk Raja ${ }^{2}$, Carolin Elizabeth George ${ }^{2}$, Bethesda O'Connell ${ }^{1}$, Priya Gangadharan ${ }^{2}$, Gift \\ Norman $^{2}$ \\ ${ }^{1}$ Liberty University, Department of Public and Community Health, United States \\ ${ }^{2}$ Bangalore Baptist Hospital, India \\ Correspondence: Bethesda O’Connell, Liberty University, Department of Public and Community Health, United \\ States
}

Received: March 6, 2019; Accepted: March 24, 2019; Published: April 30, 2019

\begin{abstract}
Introduction: Unsafe water, poor sanitation and inadequate hygiene affects many communities around the world. Without access to clean water, proper waste management, or knowledge of basic hygiene practices, the risk for disease is greatly increased. The menstrual cycle can be hard to manage without access to clean products. Additionally, poor knowledge can perpetuate unhygienic practices. Girls are often not taught about menstruation before it occurs leaving them with feelings of fear, disgust, and uncertainty.

Methods: This paper analyzes data from adolescent girls in both rural and urban communities in India concerning their knowledge, perceptions, and hygiene practices regarding menstruation. Results from pre and posttests indicate change in knowledge following an educational intervention.

Results: The knowledge and practices of adolescent Indian girls regarding menstrual hygiene were greatly lacking. In fact, $53.8 \%$ of girls did not know anything about menstruation prior to their first period. Overall, knowledge and practices improved significantly after the educational intervention.

Discussion and Conclusion: Education of girls on menstrual hygiene management is effective. The results of this study are generally consistent with other literature. Further educational and environmental interventions as well as research are needed.
\end{abstract}

Keywords: adolescent girls, menstruation, hygiene practices, perceptions, India

\section{Introduction}

Inadequate water, sanitation, and hygiene (WASH) practices affect many communities around the world. The risk for disease increases where there is a lack of knowledge on proper hygiene practices, or facilities available for managing waste. Additionally, these issues are compounded by a lack of access to clean water (Brocklehurst \& Bartram, 2010). For women, menstrual hygiene is an important health and social issue, the World Health Organization and the United Nations Children's Fund (WHO/UNICEF) defines menstrual hygiene management as: "women and adolescent girls are using a clean menstrual management material to absorb or collect menstrual blood, that can be changed in privacy as often as necessary for the duration of a menstrual period, using soap and water for washing the body as required, and having access to facilities to dispose of used menstrual management materials" (Marni, Cherenack, Blake, Murat \& Burgers, 2015). Due to low access to products and restricted education, many women and girls still use old cloth pieces instead of sanitary pads (Shanbhag, Shilpa, D'Souza, Josephine, Singh \& Goud, 2012; Paria, Bhattacharyya \& Das, 2014; Thakre et al., 2011). When the cloths are not cleaned properly and are reused over several cycles, the chances of reproductive tract infections (RTIs) and urinary tract infections (UTIs) increase (Shanbhag, Shilpa, D’Souza, Josephine, Singh \& Goud, 2012). These infections can have a debilitating effect on the reproductive health of women. A study done on WASH in schools found that $60 \%$ of women who had UTIs were reusing cloths during menstruation (Marni, Cherenack, Blake, Murat \& Burgers, 2015).

Menstruation is often seen as dirty or unclean and many girls practice restrictions (such as not attending social gatherings) during their cycle (Paria, Bhattacharyya \& Das, 2014). These perceptions, along with socioeconomic status, influence girls' ability to practice safe menstrual hygiene management (Garikipati \& Boudot, 2017). Even though menstrual education is vital to the reproductive health of women, girls are often not educated on proper 
hygiene management and have little knowledge of the physiological process that takes place during the menstrual cycle. Studies including both rural and urban populations across India show that close to half of girl's lack knowledge regarding menstruation prior to menarche (Paria, Bhattacharyya \& Das, 2014; Deo \& Ghattargi, 2005; Van eijk et al., 2016). Shanbhag et al. studied school-going girls in settings around Bangalore city and found that while $73.7 \%$ of girls knew menstruation is unique to females, only $28.7 \%$ had specific awareness on the physiological process. In fact, only $35.8 \%$ associated menarche with the ability to become pregnant (Shanbhag, Shilpa, D’Souza, Josephine, Singh \& Goud, 2012). Many girls respond to their menarche in fear, disgust, and depression, which exacerbates adaptation to the psychological and developmental changes that occur throughout the menstrual cycle (Paria, Bhattacharyya \& Das, 2014; Deo \& Ghattargi, 2005). This is due in part to the cultural and social taboos that surround the topic (Paria, Bhattacharyya \& Das, 2014; Chothe et al., 2014). Due to poor menstrual hygiene management and knowledge and the negative health and social outcomes a greater understanding and interventions are necessary.

\section{Methods}

The purpose of this study was to understand the level of knowledge of impact of education on menstrual hygiene management and perceptions in adolescent girls around Bangalore. The study includes girls ages 10 to 16 who are students at an urban slum public school and a rural school. IRB approval was obtained. Pre-test surveys to ascertain menstrual hygiene practices, knowledge, and perceptions were conducted with students. The surveys were translated and explained thoroughly by health care professionals to ensure girls had a clear understanding of the questions. An educational invention was implemented, and students were sub sequentially given a post-test for comparison.

Data were analyzed using Statistical Package for Social Sciences (SPSS for Windows, Version 24.0. Chicago, SPSS Inc.) Survey questions on knowledge were combined to create a knowledge index. Likewise, a practices index was created to summarize hygiene practices. Descriptive statistics, Chi square and correlations were used to examine socioeconomic factors, knowledge and practice indexes.

\section{Results}

Descriptive statistics were used to analyze demographics and to understand baseline information. There were 323 girls who participated in the study with the average of age of menarche at 12.2 years and most girls surveyed were in the eighth (44.7\%) and ninth (44.3\%) standard (grade). Table 1 summarizes Pretest responses to knowledge and hygiene practices questions. Table 2 summarizes the responses from the knowledge section of the pre-test including: what is menstruation, what is the cause of menstruation, what organ does the blood come from.

Table 1. Descriptive Analysis and Hygiene Practices

\begin{tabular}{|l|l|l|}
\hline Question & $\begin{array}{l}\text { Total } \begin{array}{r}\text { of } \\
\text { respondents }\end{array} \\
\text { Percentage of } \\
\text { respondents }\end{array}$ \\
\hline Did you have knowledge about menstruation before menarche? (N= 288) & & \\
\hline Yes & 133 & $46.2 \%$ \\
\hline No & 155 & $53.8 \%$ \\
\hline Who informed you about the menstrual cycle? (N= 189) & & \\
\hline Mother & 94 & $29.1 \%$ \\
\hline Teacher & 20 & $6.2 \%$ \\
\hline Friends & 48 & $14.9 \%$ \\
\hline Books & 4 & $1.2 \%$ \\
\hline Media & 2 & $0.6 \%$ \\
\hline Other & 21 & $6.5 \%$ \\
\hline Reaction to Menarche (N=240) & & \\
\hline Happy & 42 & $17.5 \%$ \\
\hline Scared & 108 & $45.0 \%$ \\
\hline Discomfort & 78 & $32.5 \%$ \\
\hline Emotional disturbance & 12 & $5.0 \%$ \\
\hline Previous menstruation education? $(\mathbf{N}=\mathbf{2 8 3})$ & & \\
\hline Yes & 38 & $13.4 \%$ \\
\hline No & 245 & $86.6 \%$ \\
\hline Which absorbent is used? (N=235) & & \\
\hline & & \\
\hline
\end{tabular}




\begin{tabular}{|l|l|l|}
\hline Commercially made sanitary pad & 173 & 73.6 \\
\hline Soft paper & 22 & 9.4 \\
\hline Rag made pad & 34 & 14.5 \\
\hline Cloth & 6 & 2.6 \\
\hline Does menstruation interfere with school performance? (N=271) & & \\
\hline Yes & 119 & $43.9 \%$ \\
\hline No & 152 & $56.1 \%$ \\
\hline Do you think a woman is unclean during menstruation? (N=242) & & \\
\hline Yes & 144 & $59.5 \%$ \\
\hline No & 98 & $40.5 \%$ \\
\hline Where do you dispose of pads? (N=238) & & \\
\hline Dustbin & 219 & $94 \%$ \\
\hline Drain & 9 & $3.9 \%$ \\
\hline Toilet & 1 & $0.4 \%$ \\
\hline Open field & 4 & $1.7 \%$ \\
\hline Burn & 5 & --- \\
\hline What do you wrap the pad in before disposing (N=231) & & \\
\hline Papers & 60 & $26.0 \%$ \\
\hline Plastic bag & 170 & $73.6 \%$ \\
\hline Not wrap & 1 & $0.4 \%$ \\
\hline When do you bathe during menstruation (N=238) & & \\
\hline Daily & 163 & $68.5 \%$ \\
\hline First Day & 46 & $19.3 \%$ \\
\hline Second Day & 26 & $10.9 \%$ \\
\hline Don't take at any time & 3 & $1.3 \%$ \\
\hline Do you clean the genitalia during menstruation (N=241) & & \\
\hline Yes & 239 & $99.2 \%$ \\
\hline No & 2 & $0.8 \%$ \\
\hline What do you clean with? (N=238) & & \\
\hline Water and soap & 129 & $54.2 \%$ \\
\hline Only water & 107 & $45.0 \%$ \\
\hline Tissue & 2 & $0.8 \%$ \\
\hline & & \\
\hline
\end{tabular}

Table 2. Menstrual Cycle Knowledge Responses

\begin{tabular}{|l|l|}
\hline What is menstruation? (N=311) & \\
\hline Physiological (normal process in girls & $140(45.2 \%)$ \\
\hline Pathological (due to some abnormality) & $2(0.3 \%)$ \\
\hline Curse & 0 \\
\hline Don't know & $169(54.5 \%)$ \\
\hline What causes menstruation(N=309) & \\
\hline Hormones & $122(39.5 \%)$ \\
\hline Curse of god & $1(0.3 \%)$ \\
\hline Caused by disease & 0 \\
\hline Don't know & $186(60.2 \%)$ \\
\hline What organ does menstrual blood come from?(N=307) & \\
\hline Uterus & $84(27.4 \%)$ \\
\hline Vagina & $25(8.1 \%)$ \\
\hline Bladder & $17(5.5 \%)$ \\
\hline Stomach & $3(1.0 \%)$ \\
\hline Don't Know & $178(58.0 \%)$ \\
\hline
\end{tabular}

The descriptive analysis results included that most girls reported that they were 12-13 when they attained menarche. About half (53.8\%) of girls reported that they had no prior knowledge of menstruation or the menstrual cycle prior 
to menarche and only $13.4 \%$ of respondents said they had received previous education regarding menstruation hygiene or the menstrual cycle. Of those informed about the menstrual cycle and menstruation, $49.7 \%$ were informed by their mothers. Another source of information regarding menstruation was friends (25.4\%). Almost half (45.0\%) of girls reported their reaction to their menarche was fear. Most of the girls viewed menstrual blood as impure (73.4\%) in the pretest and 59.5\% believed that women are unclean or impure during menstruation. Concerning hygiene and sanitation practices, the majority used commercially made sanitary pads $(73.6 \%)$.

Crosstabulations were run to see if knowledge or practices indices were impacted by whether the girls were urban or rural. Location was not correlated to knowledge or hygiene practices. Because not all pre-tests and post-tests could be paired, Chi square analysis was used to determine of there was a difference on average between pre-test and post-test responses. There were several students who completed the pre-test but did not complete the post-test as well as a number of students who completed the post-test but were not present for the pre-test. Table 3 summarized the significant Chi Square values from the pre and posttest given to the students.

Table 3. Chi Square results from pre and posttest

\begin{tabular}{|c|c|c|c|c|}
\hline Pre-test Responses & Post-test & Responses & Total (\%) & Chi Square p value \\
\hline $\begin{array}{l}\text { What is menstruation? } \\
(\mathrm{N}=299)\end{array}$ & Incorrect & Correct & & $\mathrm{p}<0.0001$ \\
\hline Incorrect & 28 & 171 & $199(66.65 \%)$ & \\
\hline Correct & 8 & 92 & $100(33.44 \%)$ & \\
\hline $\begin{array}{l}\text { What is the cause of menstruation? } \\
(\mathrm{N}=299)\end{array}$ & Incorrect & Correct & & \\
\hline Incorrect & 49 & 162 & $208(69.56 \%)$ & $\mathrm{p}<0.0001$ \\
\hline Correct & 10 & 78 & $88(29.43 \%)$ & \\
\hline $\begin{array}{l}\text { Which organ does menstrual blood come } \\
\text { from? } \\
(\mathrm{N}=299)\end{array}$ & Incorrect & Correct & & $\mathrm{p}<0.0001$ \\
\hline Incorrect & 101 & 138 & $239(79.93 \%)$ & \\
\hline Correct & 11 & 49 & $61(20.07 \%)$ & \\
\hline $\begin{array}{l}\text { How long should a period last in a normal } \\
\text { person? } \\
(\mathrm{N}=299)\end{array}$ & Incorrect & Correct & & $\mathrm{p}<0.0001$ \\
\hline Incorrect & 17 & 95 & $112(37.46 \%)$ & \\
\hline Correct & 15 & 172 & $187(62.54 \%)$ & \\
\hline $\begin{array}{l}\text { Is menstrual blood impure or } \\
\text { unhygienic? } \\
(\mathrm{N}=299)\end{array}$ & Incorrect & Correct & & $\mathrm{p}<0.0001$ \\
\hline Incorrect & 46 & 201 & $247(82.61 \%)$ & \\
\hline Correct & 14 & 38 & $52(17.39 \%)$ & \\
\hline $\begin{array}{l}\text { Can one become pregnant before } \\
\text { menarche? } \\
(\mathrm{N}=299)\end{array}$ & Incorrect & Correct & & $\mathrm{p}<0.0001$ \\
\hline Incorrect & 26 & 96 & $122(40.81 \%)$ & \\
\hline Correct & 22 & 155 & $177(59.20 \%)$ & \\
\hline $\begin{array}{l}\text { How often should you bathe during } \\
\text { menstruation? } \\
(\mathrm{N}=299)\end{array}$ & Incorrect & Correct & & $\mathrm{p}<0.0001$ \\
\hline Incorrect & 66 & 97 & $163(54.52 \%)$ & \\
\hline Correct & 18 & 118 & $136(45.48 \%)$ & \\
\hline $\begin{array}{l}\text { How should one clean the external } \\
\text { genitalia? } \\
(\mathrm{N}=299)\end{array}$ & Incorrect & Correct & & $\mathrm{p}<0.0001$ \\
\hline Incorrect & 27 & 88 & $115(38.46 \%)$ & \\
\hline Correct & 12 & 172 & $184(61.54 \%)$ & \\
\hline
\end{tabular}




\section{Discussion}

This study's findings are comparable to the current literature concerning knowledge on menstruation and hygiene practices. A similar study done in West Bengal also found that $62 \%$ of girls were not aware the reason for menstruation, consistent with $60.5 \%$ incorrect "don't know" pretest responses in this study. Another found that while $57.9 \%$ had knowledge of menstruation before menarche, only $28.7 \%$ understood or had knowledge of the actual physiological process of the menstrual cycle. This supports $53.8 \%$ of respondents in this study which had prior knowledge of menstruation but contrasts with the $45.2 \%$ who understood the physiological process found in this study (Shanbhag, Shilpa, D'Souza, Josephine, Singh \& Goud, 2012). Another study found that $21 \%$ of girls believed menstruation to be physiological process but most were unaware of the cause of it (Shanbhag, Shilpa, D'Souza, Josephine, Singh \& Goud, 2012). Another study found that $38 \%$ knew that menstruation was a normal process but only $16 \%$ of girls understood that bleeding comes from the uterus and not the vagina (Maji, 2016). A large proportion of the girls were not aware of menstruation until menarche and $45 \%$ reported feeling fear. A study done on the knowledge and practices regarding menstrual reported that $49.0 \%$ reacted in fear consistent with other research finding $45.0 \%$ having fear and $44 \%$ being upset when they experience menarche (Maji, 2016; Ramachandra, 2016).

In this study, $50.2 \%$ of girls reported receiving education about menstrual hygiene, with most responses including the need to take baths and change sanitary pads. However, only $13.4 \%$ of respondents reported being taught about the menstrual cycle in a school setting. Mothers are the most common informant of menstruation and menstrual hygiene management to their daughters (55.5\%) although friends, sibling, other female relatives, and teachers also play a role. This is consistent with another study that found that $43 \%$ of girls received their knowledge from their mothers (Marni, Cherenack, Blake, Murat \& Burgers, 2015). In both the urban and rural populations, sanitary pads were the most common absorbent used (73.6\%). A recent study showed an increased use of sanitary pads in urban slums to $56 \%$ (Garikipati \& Boudot, 2017). Another study on urban adolescent girls found that $69 \%$ of respondents used sanitary pads (Ramachandra, 2016). This finding contrasts with a previous study which found that $42.5 \%$ of girls used old cloths even if they were aware of commercially made sanitary pads (Dasgupta \& Sarkar, 2008). However, this difference could stem from the age of the study and fact that sanitary pads have been made more affordable and available (Garikipati \& Boudot, 2017).

There are several limitations to this research. Due to missing responses on surveys, there may be gaps in the data and analysis particularly concerning the descriptive analysis. This research was conducted in classroom settings where the students may have been biased to answer like their peers or been under the influence of the teachers who were present for the survey. Other sources of bias include those associated with self-report such as recall bias. An additional limitation is not pairing pretest and posttest to run additional analyses. This research has shown that many adolescent girls do not have adequate knowledge regarding the menstrual cycle. This can affect their hygiene practices.

\section{Conclusion}

This research adds to current data surrounding menstrual hygiene practices and perceptions and advocates that improved educational interventions be offered to adolescent girls to aid in reducing stigma and improving knowledge concerning the menstrual cycle and improving hygiene practices. It demonstrates that offering education within a school setting can be an effective tool in bringing awareness to good menstrual hygiene practices. Additionally, it can inform girls on what the menstrual cycle is and how it affects them physically, mentally, and emotionally.

Future work should be done to understand how socio-environmental factors affect hygiene. Additionally, school and community based educational programs should include evaluation methods of the long-term impact of educational interventions on knowledge and practices. Finally, since facilities and sanitation systems will enable or limit a girl's ability to practice good menstrual further study is needed to understand the impact of these systems on the health of girls and women.

\section{References}

Brocklehurst, C., \& Bartram, J. (2010). Swimming upstream: why sanitation, hygiene and water are so important to mothers and their daughters. Bulletin of the World Health Organization, 2010. https://doi.org/10.2471/BLT.10.080077

Chothe, V., Jagdsih, K., Seabert, D., Asalar, M., Rakshe, S., Firke, A., et al. (2014). Students' perceptions and doubts about menstruation in developing countries: A case study from India. Health Promotion Practice, 2014. https://doi.org/10.1177/1524839914525175 
Dasgupta, A., \& Sarkar, M. (2008). Menstrual Hygiene: How Hygienic is the Adolescent Girl? Indian Journal of Community Medicine: Official Publication of Indian Association of Preventive \& Social Medicine, 2008. https://doi.org/10.4103/0970-0218.40872

Deo, D. S., \& Ghattargi, C. H. (2005). Perceptions and practices regarding menstruation: A comparative study in urban and rural adolescent girls. Indian Journal of Community Medicine, 2005. Retrieved from http://medind.nic.in/iaj/t05/i1/iajt05ilp33.pdf

Garikipati, S., \& Boudot, C. (2017). To pad or not to pad: Towards better sanitary care for women in Indian slums. Journal of International Development, 2017. https://doi.org/10.1002/jid.3266

Maji, S. (2016). A study on menstrual knowledge and practices among rural adolescent girls in Burdwan district, West Bengal. International Journal of Advanced Research, 2016. https://doi.org/10.21474/IJAR01/1558

Marni, S., Cherenack, E., Blake, S., Murat, S., \& Burgers, L. (2015). WASH in schools empowers girls' education: Proceedings of the menstrual hygiene management in schools virtual conference 2014, United Nations Children's Fund and Columbia University, 2015. Retrieved from https://www.unicef.org/wash/schools/files/MHM_vConf_2014.pdf

Paria, B., Bhattacharyya, A., \& Das, S. A. (2014). Comparative Study on Menstrual Hygiene Among Urban and Rural Adolescent Girls of West Bengal. J Family Med Prim Care, 2014. https://doi.org/10.4103/22494863.148131

Ramachandra, K. (2016). A study on knowledge and practices regarding menstrual hygiene among urban adolescent girls. International Journal of Contemporary Pediatrics, 2016. https://doi.org/10.18203/23493291.ijcp20160147

Shanbhag, D., Shilpa, R., D’Souza, N., Josephine, P., Singh, J., \& Goud, B. R. (2012). Perceptions regarding menstruation and practices during menstrual cycle among high school going adolescent girls in resource limited settings around Bangalore city, Karnataka, India. International Journal of Collaborative Research on Internal Medicine and Public Health; 2012. Retrieved from http://ezproxy.liberty.edu/login?url=https://search.proquest.com/docview/1025744606?accountid=12085

Thakre, S. B., Thakre, S. S., Reddy, M., Rathi, N., Pathak, K., \& Ughade, S. (2011). Menstrual hygiene: Knowledge and practice among adolescent school girls of Saoner, Nagpur district. J ClinDiagn Res, 2011. Retrieved from https://www.researchgate.net/profile/Suresh_Ughade/publication/267415792_Menstrual_Hygiene_Knowled ge_and_Practice_among_Adolescent_School_Girls_of_Saoner_Nagpur_District/links/54c7c3620cf289f0ce $\mathrm{cdc} 3 \mathrm{eb} /$ Menstrual-Hygiene-Knowledge-and-Practice-among-Adolescent-School-Girls-of-Saoner-NagpurDistrict.pdf

Van eijk, A. M., Sivakami, M., Thakkar, M., Bauman, A., Laserson, K., Coates, S., et al. (2016). Menstrual hygiene management among adolescent girls in India: A systematic review and meta-analysis. BMU Open, 2016. https://doi.org/10.1136/bmjopen-2015-010290

\section{Copyrights}

Copyright for this article is retained by the author(s), with first publication rights granted to the journal.

This is an open-access article distributed under the terms and conditions of the Creative Commons Attribution license (http://creativecommons.org/licenses/by/4.0/). 